\title{
Seepage analysis of soil column under the condition of rainfall evaporation
}

\author{
Chen Jiang-hu \\ Nanchang Institute of Building Science \\ Nanchang, China \\ 490901533@qq.com
}

\author{
Mei Guo-xiong \\ Guangxi University \\ Guangxi, China
}

\begin{abstract}
In this paper, a soil column model is built by using VADOSE/W module in Geostudio software. The numerical simulation analysis is carried out by taking into account the effects of rainfall, gas diffusion, evaporation and vegetation transpiration, in order to explore the change law of volume water content in soil column and the influence of rainfall and rainfall duration on the change of rainfall and evaporation. The results show that when the permeability coefficient is constant, the surface of the soil column has a great influence on the surface of the soil column, but with the time prolonging, the depth is larger, and there is a critical rainfall.
\end{abstract}

Keywords—soil column; evaporation; rainfall; rainfall duration

\section{INTRODUCTION}

The spatial distribution and variation law of water in soil is closely related to the evaporation conditions and the properties of soil, The spatial distribution of soil moisture content in the soil has been obtained by the experimental test[1-3]. But not finding a suitable curve to describe its change law and its significance. In addition, the effects of rainfall and rainfall duration on the spatial distribution of soil moisture in the soil are discussed. This is the main work of this paper.

\section{UNSATURATED SEEPAGE FINITE ELEMENT ANALYSIS}

In this paper, the VADOSE/W finite element software is used in the numerical simulation analysis to get spatial distribution and variation of soil moisture under the condition of evaporation. The software can take into account the impact of rainfall, surface water infiltration, groundwater, surface evaporation and vegetation transpiration and other factors.

\section{A. Computational assumptions and models}

If the soil column is homogeneous expansive soil, the initial state of the soil column is saturated. Simplify it into a onedimensional problem, and the finite element model is shown in Fig.1. The upper boundary of the model is the boundary of the atmosphere, and the other boundary is impermeable boundary, and the recharge of groundwater is not taken into account.

\section{B. Calculation parameters and scheme}

The soil permeability function curve describes the relationship between the unsaturated soil matrix suction and the per- meability coefficient. In this paper, the method is used to predict the soil permeability coefficient function, and the fitting

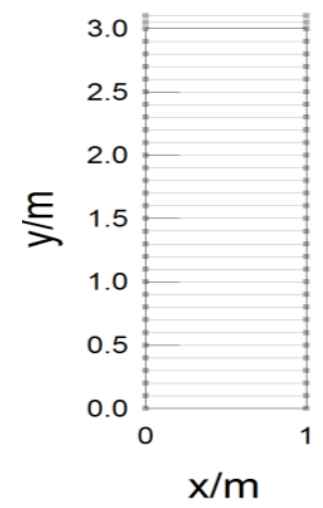

Fig. 1 soil column grid model

method of Fredlund \& Xing is proposed, and the control equation is obtained by integrating the integral of the volume water content function $^{[4]}$ :

$$
k_{w}=k_{s} \frac{\sum_{i=j}^{N} \frac{\theta\left(e^{y}\right)-\theta(\psi)}{e^{y i}} \theta^{\prime}\left(e^{y i}\right)}{\sum_{i=j}^{N} \frac{\theta\left(e^{y}\right)-\theta_{s}}{e^{y i}} \theta^{\prime}\left(e^{y i}\right)}
$$

Among them, the $\mathrm{k}_{\mathrm{w}}$ is permeability coefficient, the $\mathrm{k}_{\mathrm{s}}$ is saturation permeability coefficient, the e is natural logarithm, the $\theta$ is volume water content, the $\theta_{\mathrm{s}}$ is saturated volume water content, the $\phi$ is matrix suction.

Soil water characteristic curve (SWCC) refers to the relationship between the soil suction and volumetric water content of unsaturated soil, which reflects the water holding capacity of the soil in unsaturated soil.

The soil water characteristic curve used in this paper is measured by an expansive soil, and the hysteresis effect is neglected, as shown in Fig. 2. The saturated permeability coefficient is $2.56 \mathrm{e}-3 \mathrm{~m} / \mathrm{d}$, and the relationship between the permeability coefficient and the suction is shown in Fig. 3.

The calculation time is 40 days and the first 20 days is a continuous evaporation time. Then it continues to evaporate 
after rainfall. Rainfall duration and rainfall intensity are shown in Table 1, which is divided into six kinds of working conditions. The intensity is $50 \mathrm{~mm} / \mathrm{d}, 10 \mathrm{~mm} / \mathrm{d}, 30 \mathrm{~mm} / \mathrm{d}$. The total rainfall amount is $210 \mathrm{~mm}$, which lasted for 2 days, 3 days,

5 days, 7 days. The climate conditions are selected from the experimental data in the literature ${ }^{[5]}$, which changes the rainfall in a reasonable range. The climate conditions of two of the working conditions are shown in Fig.4 and Fig. 5.

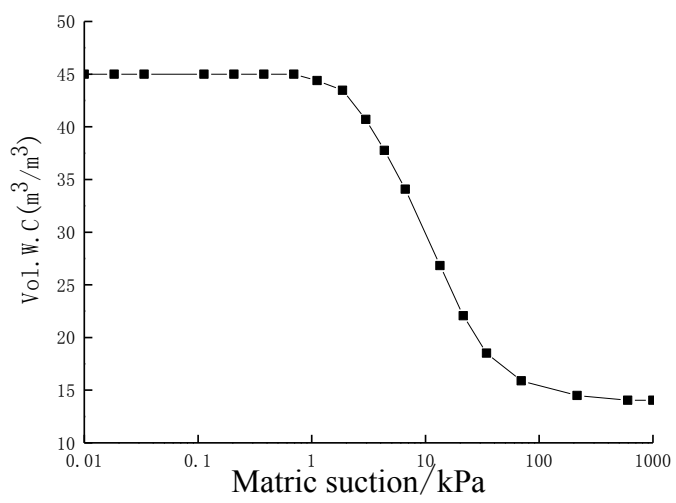

Fig. 2 The soil-water characteristic curve

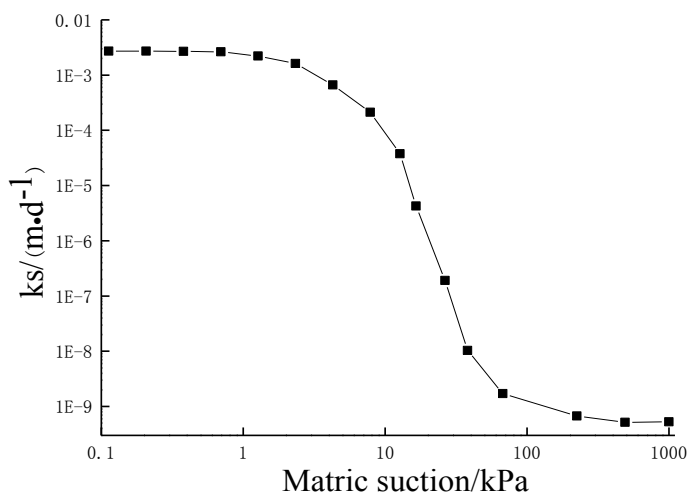

Fig. 3 Relation of permeability coefficient and suction

TABLE I. DIFFERENT WORKING CONDITION

\begin{tabular}{|l|l|c|c|}
\hline \multicolumn{2}{|l|}{ Working conditions } & $\begin{array}{l}\text { Rainfall intensi- } \\
\text { ty }(\mathrm{mm} / \mathrm{d})\end{array}$ & $\begin{array}{l}\text { rainfall } \\
\text { duration } \\
(\mathrm{d})\end{array}$ \\
\hline \multirow{2}{*}{$\begin{array}{l}\text { Same time } \\
\text { Different rain- } \\
\text { fall intensity }\end{array}$} & condition 1 & 10 & 7 \\
\cline { 2 - 4 } & condition 2 & 20 & 7 \\
\cline { 2 - 4 } & condition 3 & 30 & 7 \\
\hline $\begin{array}{l}\text { Same amount } \\
\text { of rainfall } \\
\text { Different time }\end{array}$ & condition 4 & 50 & 7 \\
\cline { 2 - 4 } & condition 5 & 42 & 5 \\
\cline { 2 - 4 } & condition 6 & 70 & 2 \\
\hline
\end{tabular}

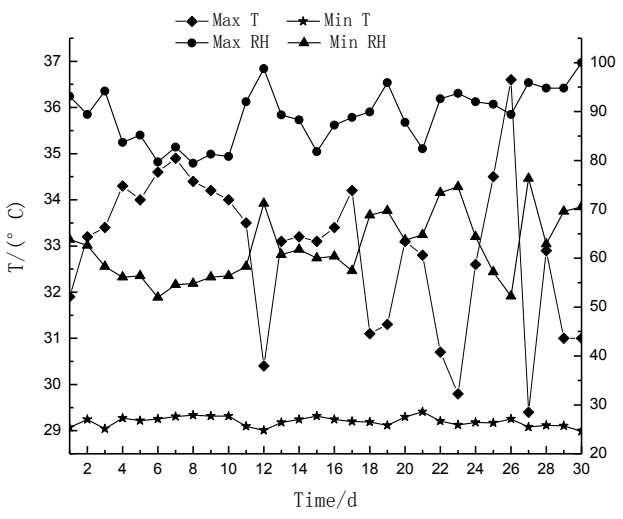

Fig. 4 The temperature and humidity change with time

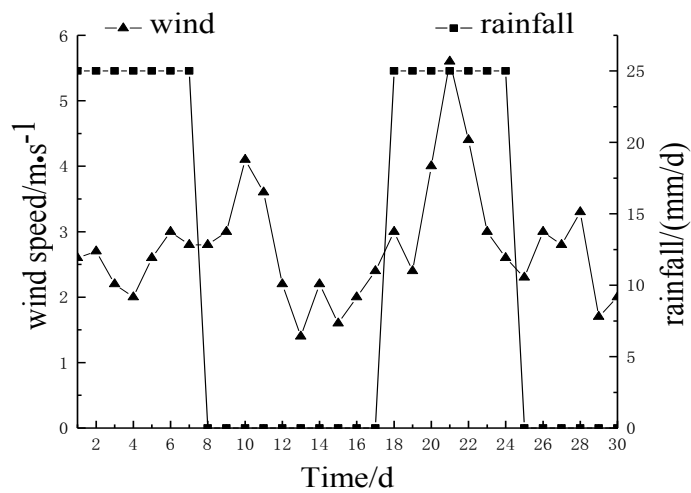

Fig. 5 The wind speed and rainfall change with time

\section{CALCULATION RESULTS ANALYSIS}

\section{A. Evaporation stage analysis}

The formula (2) is used to describe the volume water content distribution and the characteristics of water movement in the soil column under the condition of rainfall and evaporation:

$$
\theta_{w}=\theta_{w 0}+\Delta \theta_{w \max } e^{-n z}
$$

The $\theta_{\mathrm{w}}$ is volume water content that refers to the total volume content of the volume of water in the soil for soil ratio. The $\mathrm{z}$ is buried deep. The $\Delta \theta_{\text {wmax }}$ is volume water content of the biggest changes in the amount and $\theta_{\mathrm{w} 0}$ is the initial water volume. The $\mathrm{n}$ is a variable moisture distribution coefficient, which is related to the buried depth, permeability coefficient and rainfall duration. When $\mathrm{z}=\mathrm{zero}$ or $\mathrm{z}$ is close to zero, there is a volume of water content in the surface soil of a certain day. For saturated soil column, it can be considered as the saturated volume water content.

In addition, because of the difference of the climatic conditions, the difference of saturated permeability coefficient, the evaporation intensity is different and the $\Delta \theta_{\text {wmax }}$ is also different.

In the early days of evaporation, soil column began to lose moisture and the surface soil is more intense, with the depth of the soil depth, the evaporation effect is gradually weakened, and the water loss is slow. After 20 days of continuous evaporation, it can be seen that the early stage of evaporation and soil 
column volume water content is affected by the depth of the atmosphere in the $2.9 \mathrm{~m}$. Moreover, the surface of the soil moisture changes from 0.45 to 0.35 and reduced by 22.2 percent.

For $\mathrm{x}=0.5 \mathrm{~m}$ section, Fig. 6 shows the volume water content of first days, third days, fifth days, days, seventh days, ninth days, eleventh days, thirteenth days, fifteenth days, seventeenth days, twentieth days.

The curve was fitted by using formula (2) and the fitting results are shown in Table 2. Therefore, it can be used to describe the distribution of moisture in the soil column under the evaporation condition.

\section{B. Rainfall infiltration analysis}

Fig. 7, Fig. 8, Fig. 9, Fig. 10 show the distribution of the soil moisture content of the soil under the conditions 1, 2, 3, 4 . For condition 1, the surface soil moisture content reached 0.365 , an increase of 0.015 in the first day of rainfall and a turning point appeared in the second day. While condition 3, 4, the water content reached 0.402 , an increase of 12.9 percent, and a significant turning point, but the condition 2 is not.

The turning point means that the soil moisture distribution is uneven, and the hydraulic gradient increases. For the continuous rainfall, the soil column water content affected by the depth of the different conditions. Conditions 1 is $1.5 \mathrm{~m}$ and conditions 2, 3, 4 are $2.9 \mathrm{~m}$, but the range of significant changes is $1.5 \mathrm{~m}$. That is, in a certain range, the greater the rainfall intensity, the greater the impact depth.

TABLE II. FITTING RESULTS OF VOLUMETRIC WATER CONTENT WITH DEPTH

\begin{tabular}{|c|c|c|c|c|}
\hline time/d & $\boldsymbol{\theta}_{w \mathbf{0}}$ & $\Delta \boldsymbol{\theta}_{\boldsymbol{w} \max }$ & $\mathbf{n}$ & $\mathbf{R}^{\mathbf{2}}$ \\
\hline 1 & 0.450 & -0.003 & 6.792 & 0.997 \\
\hline 3 & 0.450 & -0.020 & 2.741 & 0.987 \\
\hline 5 & 0.451 & -0.033 & 2.029 & 0.994 \\
\hline 7 & 0.451 & -0.047 & 1.694 & 0.985 \\
\hline 9 & 0.452 & -0.059 & 1.456 & 0.980 \\
\hline 11 & 0.453 & -0.071 & 1.326 & 0.991 \\
\hline 13 & 0.454 & -0.076 & 1.124 & 0.995 \\
\hline 15 & 0.455 & -0.084 & 1.050 & 0.986 \\
\hline 17 & 0.455 & -0.093 & 1.036 & 0.992 \\
\hline 20 & 0.455 & -0.103 & 0.974 & 0.988 \\
\hline
\end{tabular}

The distribution of water content condition 3 and condition 4 of the working condition is approximately the same. Under the above mentioned conditions, the greater the rainfall intensity, the greater the distribution of soil moisture content. And there is a critical rainfall intensity, which is related to the permeability coefficient and the initial water content of soil.

By comparison analysis, the critical rainfall intensity is $30 \mathrm{~mm} / \mathrm{d}$, which is more than that of the rainfall intensity, and has little effect on the distribution of soil moisture content. According to the conditions 5, 6, 7 can also be confirmed this, when the total amount of rainfall, after the full infiltration, soil column moisture distribution is almost the same. When the rainfall is large and time is not enough, it is easy to lead to surface runoff, soil porosity, rapid closure.

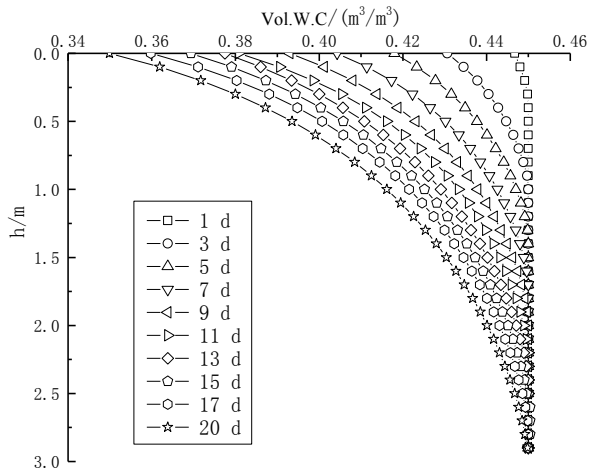

Fig. 6 moisture content distribution and fitting curve of evaporation stage

The distribution of water content of 3 and 4 is approximately the same as that of the above mentioned conditions and not the larger the rainfall intensity, the greater the distribution of soil moisture content, and the existence of a critical rainfall intensity, which is related to the soil permeability coefficient and the initial water cut.

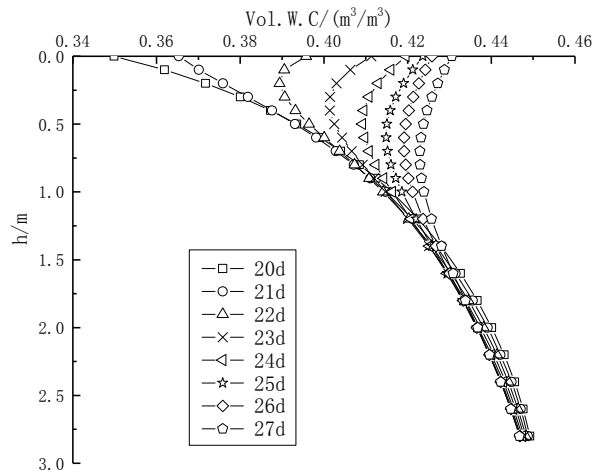

Fig. 7 working condition $1(10 \mathrm{~mm} \times 7 \mathrm{~d})$

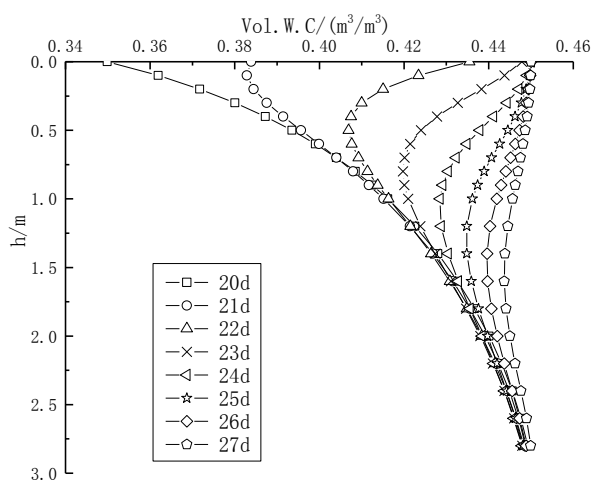

Fig. 8 working condition $2(20 \mathrm{~mm} \times 7 \mathrm{~d})$ 


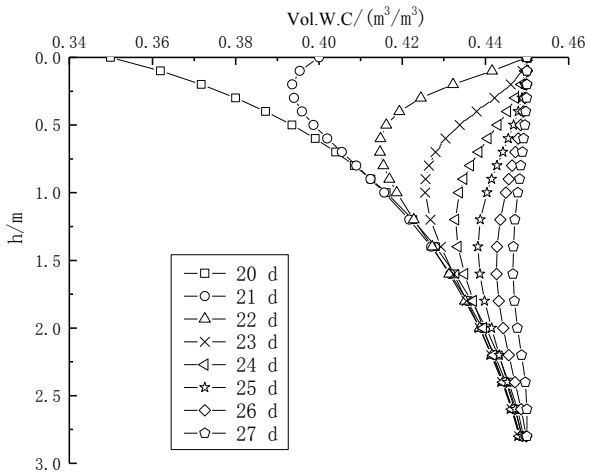

Fig. 9 working condition $3(30 \mathrm{~mm} \times 7 \mathrm{~d})$

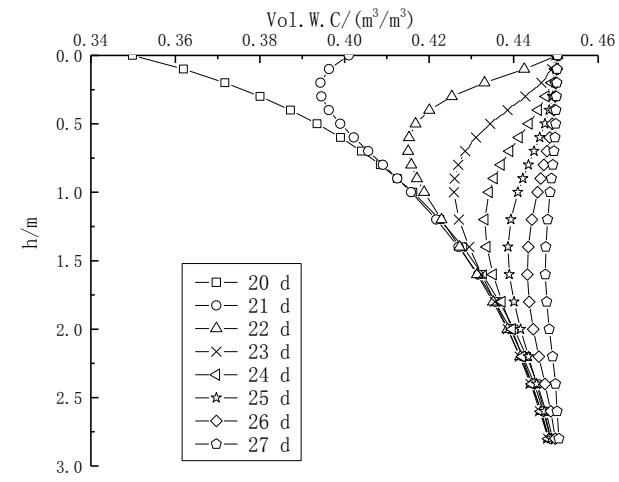

Fig. 10 working condition $4(50 \mathrm{~mm} \times 7 \mathrm{~d})$

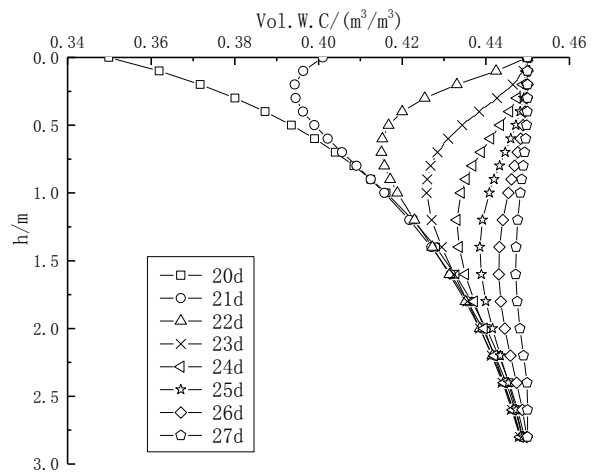

Fig. 11 working condition $5(42 \mathrm{~mm} \times 5 \mathrm{~d})$

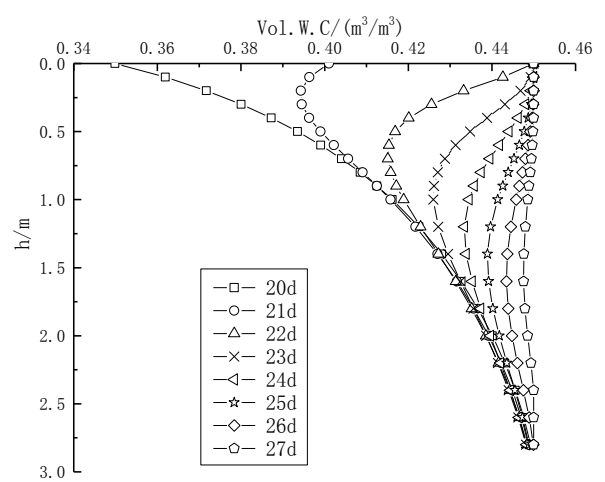

Fig. 12 working condition $6(70 \mathrm{~mm} \times 3 \mathrm{~d})$

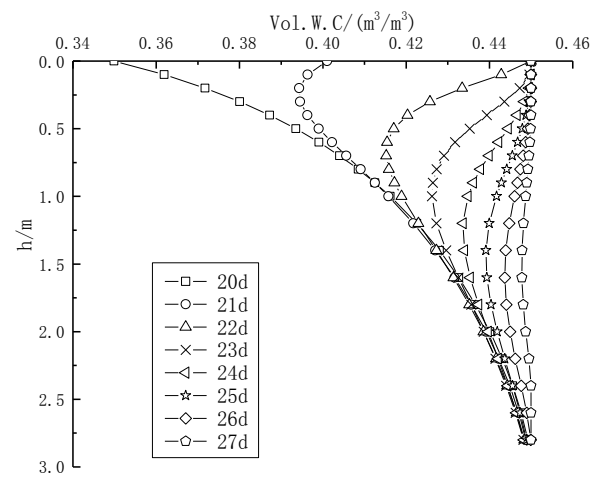

Fig. 13 working condition $7(105 \mathrm{~mm} \times 2 \mathrm{~d})$

\section{CONCLUSION}

Through numerical simulation, the results show that evaporation has a greater impact on the surface of the soil column, and with the time prolonging, the influence is deeper. The formula (2) can be used to describe the distribution of soil moisture content and its changing law, which is a reference for the following research. For the soil with the specific permeability coefficient, there is a critical rainfall, when the rainfall is the critical rainfall, the rainfall is higher, and the impact on the volume water content of the soil column is more significant. When rainfall exceeds the critical rainfall, the effect is not obvious. When the rainfall amount is the same, the duration is shorter, the surface runoff and the air hole is closed, the more the water infiltration is not enough.

\section{REFERENCES}

[1] Lu Z H, Chen Zh H. A CT study on the crack evolution of expansive soil during drying and wetting cycles[J]. Rock and Soil Mechanics, 2002, 23(4): 417-422.

[2] Gens, Alonso. A framework for the behavior of unsaturated expansive clays[J].Canadian Geotechnique Journal, 1992,Vol,19: 1013-1032.

[3] Vanapalli SK, Fredlund DG, Pufahl D Eand Clifton A W. Model for the prediction of shear strength with respect to soil suction [J]. Canadian Geotechnical Journal. 1996, 33(3): 379-392.

[4] Fredlund D.G., Morgenstern N.R., Widger R.A. The shear strength of unsaturated soils[J]. Canadian Geotechnical, 1978,15: 313-321.

[5] Geostudio Tutorials (First Edition) [M]. Cannda; GEO-SLOPE International Ltd, 2004 